\title{
Elevated Anti-SARS-CoV-2 Antibodies and IL-6, IL-8, MIP-1 $\beta$, Early Predictors of Severe COVID-19
}

\author{
Helena Codina ${ }^{1, t, \ddagger}$, Irene Vieitez ${ }^{2,+, \ddagger}$, Alicia Gutierrez-Valencia ${ }^{3}$, Vasso Skouridou ${ }^{4}$, Cristina Martínez ${ }^{5}$ (D), \\ Lucía Patiño ${ }^{1, \ddagger}$, Mariluz Botero-Gallego ${ }^{4}$, María Trujillo-Rodríguez ${ }^{3}{ }^{\circledR}$, Ana Serna-Gallego ${ }^{3}$,

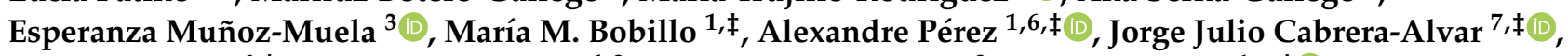

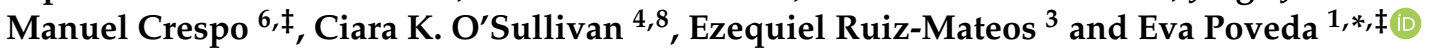

1 Group of Virology and Pathogenesis, Galicia Sur Health Research Institute (IIS Galicia Sur), SERGAS-UVigo, 36213 Vigo, Spain; helena.codina@iisgaliciasur.es (H.C.); lucia.patino@iisgaliciasur.es (L.P.); maria.marcos@iisgaliciasur.es (M.M.B.); alexandre.perez@iisgaliciasur.es (A.P.)

2 Rare Diseases \& Pediatric Medicine Research Group, Galicia Sur Health Research Institute (IIS Galicia Sur), SERGAS-Uvigo, 36213 Vigo, Spain; irene.vieitez@iisgaliciasur.es

3 Clinic Unit of Infectious Diseases, Microbiology and Preventive Medicine, Institute of Biomedicine of Seville, IBiS, Virgen del Rocío University Hospital/CSIC/University of Seville, 41013 Seville, Spain; Alicia.gutierrez.valencia@gamil.com (A.G.-V.); maria_tr_5@hotmail.com (M.T.-R.); anasernagallego@gmail.com (A.S.-G.); esperanzamunnozm@gmail.com (E.M.-M.); ezequiel.ruizmateos@gmail.com (E.R.-M.)

check for updates

Citation: Codina, H.; Vieitez, I.; Gutierrez-Valencia, A.; Skouridou, V.; Martínez, C.; Patiño, L; Botero-Gallego, M.; Trujillo-Rodríguez, M.; Serna-Gallego, A.; Muñoz-Muela, E.; et al. Elevated Anti-SARS-CoV-2 Antibodies and IL-6, IL-8, MIP-1 $\beta$, Early Predictors of Severe COVID-19. Microorganisms 2021, 9, 2259. https://doi.org/10.3390/ microorganisms 9112259

Academic Editors: Pavel Bostik and Shubhada Bopegamage

Received: 8 October 2021

Accepted: 22 October 2021

Published: 29 October 2021

Publisher's Note: MDPI stays neutral with regard to jurisdictional claims in published maps and institutional affiliations.

Copyright: (๑) 2021 by the authors. Licensee MDPI, Basel, Switzerland. This article is an open access article distributed under the terms and conditions of the Creative Commons Attribution (CC BY) license (https:// creativecommons.org/licenses/by/ $4.0 /)$.
4 INTERFIBIO Consolidated Research Group, Departament d' Enginyeria Quimica, Universitat Rovira i Virgili, 43003 Tarragona, Spain; Vasso.Skouridou@urv.cat (V.S.); Mariluz.Botero@urv.cat (M.B.-G.); ciara.osullivan@urv.cat (C.K.O.)

5 Methodology and Statistics Unit, Galicia Sur Health Research Institute (IIS Galicia Sur)-Complexo Hospitalario Universitario de Vigo, SERGAS-UVigo, 36213 Vigo, Spain; cristina.martinez@iisgaliciasur.es

6 Infectious Diseases Unit, Department of Internal Medicine, Complexo Hospitalario Universitario de Vigo, IIS Galicia Sur, SERGAS-UVigo, 36213 Vigo, Spain; manuel.crespo.casal@sergas.es

7 Microbiology Service, Galicia Sur Health Research Institute (IIS Galicia Sur), SERGAS-Uvigo, 36213 Vigo, Spain; Jorge.julio.cabrera.alvargonzalez@sergas.es

8 Institució Catalana de Recerca i Estudis Avançats, 08010 Barcelona, Spain

* Correspondence: eva.poveda.lopez@sergas.es; Tel.: +34-986-21-74-63; Fax: +34-986-800-096

+ These authors contributed equally to this work.

$\ddagger$ On behalf of the Cohort COVID-19 of the Galicia Sur Health Research Institute.

Abstract: Viral and host immune kinetics during acute COVID-19 and after remission of acute symptoms need better characterization. SARS-CoV-2 RNA, anti-SARS-CoV-2 IgA, IgM, and IgG antibodies, and proinflammatory cytokines were measured in sequential samples from hospitalized COVID-19 patients during acute infection and six months following diagnosis. Twenty four laboratory confirmed COVID-19 patients with mild/moderate and severe COVID-19 were included. Most were males $(83 \%)$ with a median age of 61 years. Twenty one percent were admitted to the intensive care unit (ICU) and eight of them (33.3\%) met the criteria for severe COVID-19 disease. A delay in SARS-CoV-2 levels' decline during the first six days of follow up, and viral load persistence until month 3 were related to severe COVID-19, but not viral load levels at the diagnosis. Higher levels of anti-SARS-CoV-2 IgA, IgM, IgG and the cytokines IL-6, IL-8 and MIP-1 $\beta$ at the diagnosis time were related to the severe COVID-19 outcome. Higher levels of MIP-1 $\beta$, IL-1 $\beta$, MIP- $1 \alpha$ and IFN- $\gamma$ were observed at month 1 and 3 during mild/moderate disease, compared to severe COVID-19. IgG persisted at low levels after six months of diagnosis. In conclusion, higher concentrations of $\operatorname{IgA}, \operatorname{IgM}$, and IgG, and IL-6, IL- 8 and MIP-1 $\beta$ are identified as early predictors of COVID-19 severity, whereas no significant association is found between baseline SARS-COV-2 viral load and COVID-19 severity.

Keywords: SARS-CoV-2; severe COVID-19; anti-SARS-CoV-2 antibodies; cytokines; viral load 


\section{Introduction}

Coronavirus disease 2019 (COVID-19), caused by severe acute respiratory syndrome coronavirus 2 (SARS-CoV-2), rapidly spread worldwide, becoming a global public health emergency. COVID-19 can be asymptomatic or mild in most cases, but it can rapidly progress to a severe lung inflammation leading to acute respiratory distress syndrome (ARDS), especially in older adults ( $>80$ years) and/or those with comorbidities (i.e., serious heart conditions, chronic pulmonary disease, diabetes mellitus, or hypertension among others) [1-3]. The disease outcome mainly depends on the characteristics of the viral replication and host immune responses, which can end up resolving the infection efficiently or creating an exacerbated inflammation associated with severe lung damage pathology, organ failure and poor outcomes. Regarding the host immune responses, SARS-CoV-2 antibody levels follow a general pattern: $\operatorname{IgM}$ and $\operatorname{IgA}$ are detectable at day 2-5 post symptom onset and levels decrease at week 3 , whereas $\operatorname{IgG}$ responds later than $\operatorname{IgA}$ and $\operatorname{IgM}$, being detectable around 10 days after the onset of symptoms and the maximum levels are reached at 30-35 days [4-6]. Although the dynamics of $\operatorname{IgM}, \operatorname{IgA}$ and IgG during the first weeks of infection have been broadly described, there are few studies reporting results beyond 40 days after symptom onset $[7,8]$. Finally, another important factor related to the severity of COVID-19 is the so called cytokine storm. The severe deterioration of some patients is closely related to the excessive and prolonged cytokine and chemokine responses induced by the SARS-CoV-2 virus [9]. Higher serum levels of proinflammatory cytokines have been observed in many patients with severe COVID-19, compared with individuals with mild disease $[10,11]$. The dynamics of proinflammatory cytokines during the first weeks of COVID-19 infection has also been reported, but long term analyses are still lacking.

Therefore, the comprehensive long term kinetics of SARS-CoV-2 RNA levels, antiSARS-CoV-2 antibodies (i.e., IgA, IgM, and IgG) and specific proinflammatory cytokines during and after COVID-19 are not fully characterized, and these are of great interest for the identification of early predictive biomarkers of severe disease and to understand the clinical outcomes of patients after the remission of acute symptoms.

This study comprises an evaluation of clinical, virological and immunological responses in a well characterized cohort of hospitalized COVID-19 patients with mild/ moderate and severe disease. We performed a close follow up at different time points, from the time of diagnosis and up to 6 months after the confirmation of the SARS-CoV- 2 infection. Moreover, we were able to identify viral and host immune biomarkers associated with COVID-19 severity. A delay in SARS-CoV-2-RNA clearance in the upper respiratory tract during the first days of the disease, higher concentrations of anti-SARS-CoV-2 IgA, IgM, and IgG and of specific cytokines (i.e., IL-6, IL-8 and MIP-1 $\beta$ ) at baseline were associated with COVID-19 severity. Overall, after 6 months, anti-SARS-CoV-2 IgG persisted, although at low levels.

\section{Materials and Methods}

\subsection{Patients, Sample Collection and Clinical Data}

The study population was selected from the COVID-19 Cohort of the Galicia Sur Health Research Institute (COHVID-GS) (https: / / www.iisgaliciasur.es/apoyo-a-la-inve stigacion/ cohorte-covid19/, accessed on 15 April 2020). This cohort includes laboratory confirmed SARS-CoV-2 patients in clinical follow up at the Vigo Healthcare Area with epidemiological/clinical data and with a repository of biological samples (i.e., nasopharyngeal swabs, serum, plasma and peripheral blood mononuclear cells-PBMCs) stored at the Galicia Sur Health Research Institute Biobank. The epidemiological/clinical information was collected in a case report form (CRF) specifically predesigned for the COHVID-GS. The cohort also includes a control group of uninfected individuals (anti-IgA, IgM and IgG SARS-CoV-2 negative). The study was approved by the Galician Clinical Research Ethics Committee (CEIm-g, ref: 2020/196, signed on 10 April 2020) and all patients signed the informed consent. All the techniques were performed in BLS-2 conditions, according to 
the biosafety guidelines for handling and processing specimens associated with COVID19 (https: / / www.cdc.gov / coronavirus / 2019-ncov/lab/lab-biosafety-guidelines.html, accessed on 25 January 2021).

The selection criteria for this study were SARS-CoV-2 adult hospitalized patients with a very close clinical follow up with nasopharyngeal swabs, serum and plasma samples, with consecutive samples available at least at baseline, day 3 or 6 , and month 1 or 3 from their inclusion in the COHVID-GS. Moreover, only those patients included in the COHVID-GS between day 1 and 5, following the confirmation of the SARS-CoV-2 infection by RT-qPCR, were considered. Serial paired nasopharyngeal swabs, and serum and plasma samples were collected from each patient at baseline, day 3 or 6 , month 1 or 3 and at month 6 . We also included 30 serum samples from healthy and noninfected individuals as controls for the immunoassay experiments. Epidemiological and clinical data were recorded for the study population.

Following WHO guidance, severe COVID-19 was defined as the need for invasive mechanical ventilation, the development of acute respiratory distress syndrome $\left(\mathrm{PO}_{2} / \mathrm{FiO}_{2}<300 \mathrm{mmHg}\right.$ or Saturation $\left.\mathrm{O}_{2} / \mathrm{FiO}_{2}<330\right)$ or admission to an intensive care unit (ICU) [12]. Patients who did not meet severe criteria were considered mild/moderate COVID-19.

\subsection{SARS-CoV-2 RNA Extraction}

Viral RNA was extracted from $140 \mu \mathrm{L}$ of nasopharyngeal swab samples using the QIAmp viral RNA mini kit (QIAGEN, Hilden, Germany) and the automatized QIAcube system (QIAGEN, Hilden, Germany), and was eluted in $50 \mu \mathrm{L}$ of buffer following the manufacturer's instructions. The positive (EDX SARS-CoV-2 Standard, Exact Diagnostics, Forth Worth, TX, USA) and negative (EDX SARS-CoV-2 Negative, Exact Diagnostics, Forth Worth, TX, USA) controls were also extracted using the same procedure.

\subsection{Droplet Digital PCR Analysis}

SARS-CoV-2 viral load was quantified by reverse transcriptase droplet digital PCR (RT-ddPCR), including the one-step reverse transcription (One-Step RT-ddPCR Advanced Kit for Probes, Bio-Rad Laboratories, Hercules, CA, USA) and the triplex probe assay for PCR amplification (2019-nCoV CDC ddPCR Triplex Probe Assay, Bio-Rad Laboratories, Hercules, CA, USA). The assay contains primers and probes targeting two regions of the SARS-CoV-2 nucleocapsid gene (N1 and N2) and the human Rnase P gene (RPP30). The reaction mixture was performed with $5.5 \mu \mathrm{L}$ of SARS-CoV-2 RNA sample and following the manufacturer's instructions. All the samples were tested in duplicate. Data analysis was performed using the QuantaSoft Analysis Pro Software (v. 1.0.596, Bio-Rad Laboratories, Hercules, CA, USA), which showed the results as copies per microliter of $1 \mathrm{x}$ ddPCR reaction. All viral load values were recalculated to copies per milliliter of swab, and the sensitivity threshold was 100 copies/mL. To assess the accuracy of the absolute viral RNA quantification, two fold serial dilutions of the positive control were analyzed for lineal regression analysis. Finally, to establish a reliable comparison between the viral load of different samples, the absolute quantification of SARS-CoV-2 RNA was normalized with RPP30 and expressed as copies $/ 10^{4}$ cells (Figure S1).

\subsection{Anti-SARS-CoV-2 IgA, IgG, and IgM Quantification}

The wells of 96-well immunoassay plates (MaxiSorp-Nunc, Thermo Fisher Scientific Inc, Waltham, MA, USA) were coated overnight at $4{ }^{\circ} \mathrm{C}$ with $50 \mu \mathrm{L}$ of $5 \mu \mathrm{g} / \mathrm{mL}$ of SARSCoV-2 nucleoprotein (NP) (ref. MBS596190 - MyBiouSource Inc, San Diego, CA, USA) in $50 \mathrm{mM}$ carbonate buffer $\mathrm{pH}$ 9.4. The wells were washed three times with $200 \mu \mathrm{L}$ of PBS containing $0.05 \%(v / v)$ Tween-20 (PBST) and then blocked with $200 \mu \mathrm{L}$ of $5 \%(w / v)$ skim milk in PBST for 30 min. After another washing step, $50 \mu \mathrm{L}$ of serum samples (diluted $1 / 100$ with PBS after heating for $30 \mathrm{~min}$ at $56{ }^{\circ} \mathrm{C}$ to inactivate residual virus) were added to the wells and incubated for $1 \mathrm{~h}$. The wells were washed again three times with PBST 
and $50 \mu \mathrm{L}$ of antihuman IgA-HRP (ref. PA174395-Thermo Fisher Scientific Inc, Waltham, MA, USA), antihuman IgM-HRP (ref. 31415-Thermo Fisher Scientific Inc, Waltham, MA, USA) or antihuman IgG-HRP (ref. A0170-Sigma, San Luis, MO, USA) enzyme conjugates diluted 1/20000 with PBST were added. After a final incubation for $30 \mathrm{~min}$, the wells were washed five times with PBST and $50 \mu \mathrm{L}$ of TMB Super Sensitive ELISA substrate was added in each well. The reaction was stopped by the addition of $50 \mu \mathrm{L}$ of $1 \mathrm{M} \mathrm{H}_{2} \mathrm{SO}_{4}$ after $5 \mathrm{~min}$, for IgM and IgA detection, or $7 \mathrm{~min}$, for IgG detection. The absorbance at $450 \mathrm{~nm}$ was finally read on a SPECTRAmax 340PC-384 microplate reader. The levels of IgA, IgM and IgG antibodies in each sample were estimated using standard antibody calibration curves. Particularly, serial dilutions of each antibody, standard IgA (ref. 31148-Thermo Fisher Scientific Inc, Waltham, MA, USA), IgM (ref. 31146) or IgG (MP Biomedical—ref. 0855908-Thermo Fisher Scientific Inc, Waltham, MA, USA), were performed with $50 \mathrm{mM}$ carbonate buffer $\mathrm{pH} 9.4$ (dilution factor $1 / 4$ ) in the range of $3.9 \mathrm{ng} / \mathrm{mL}-16 \mu \mathrm{g} / \mathrm{mL}$ for IgA and IgG and $1.9 \mathrm{ng} / \mathrm{mL}-8 \mu \mathrm{g} / \mathrm{mL}$ for IgM, and were used to coat duplicate wells in parallel with the NP coating step for sample analysis. The serum samples were analyzed on NPcoated wells in triplicate, while duplicate control (noncoated) wells were also included to eliminate any signals resulting from nonspecific binding of serum components to the wells. Calibration curves for each antibody type (IgA, IgM or IgG) were constructed by fitting the absorbance values (A450 $\mathrm{nm}$ ) to a sigmoidal 4-parameter logistical model using GraphPad Prism. The concentration of each antibody was then interpolated from its corresponding calibration curve using the corrected (A-A0) values for each sample, where A was the average absorbance of the NP-coated wells and A0 the average absorbance of the control (noncoated) wells. Prepandemic serum samples $(n=30)$ were used as controls to set the background values of the in house developed ELISA. All incubation steps were performed at room temperature $\left(22-25^{\circ} \mathrm{C}\right)$ unless stated otherwise.

\subsection{Plasma Cytokines Quantification}

Plasma cytokines concentrations were determined using enzyme linked immunosorbent assays. Interleukin-6 (IL-6), interleukin-8 (IL-8), interleukin 1 beta (IL-1 $\beta$ ), tumor necrosis factor-alpha (TNF- $\alpha$ ), interferon-gamma (IFN- $\gamma$ ), macrophage inflammatory proteins 1 alpha (MIP- $1 \alpha$ ) and 1 beta (MIP-1 $\beta$ ) were analyzed using a multiplex bead based immunoassay (MILLIPLEX ${ }^{\circledR}$ MAP Human High Sensitivity T Cell Magnetic Bead Panel, Merck KgaA, Darmstadt, DE, USA). Interferon gamma induced protein 10 (IP-10) (Human CXCL10 ELISA kit, Abcam, Cambridge, UK) and soluble receptor of interleukin 2 (sCD25) were analyzed using the Human Quantikine Immunoassay (R\&D Systems, Minneapolis, MN, USA). All followed the manufacturer's instructions.

\subsection{Statistics}

The descriptive analyses were reported as frequencies and percentages for categorical variables, and medians and interquartile ranges (IQRs) for continuous variables. To compare antibody levels between COVID-19 patients and a peer control group, and to compare SARS-CoV-2 viral load and cytokines between severe and mild/moderate patients, MannWhitney $\mathrm{U}$ test was performed. To assess the differences in the viral load over time, and the concentration of cytokines at several time points during the first 6 months after SARS-CoV2 infection, a Wilcoxon Signed Rank test was performed. Finally, Mann-Whitney U test was also used to compare the baseline antibodies levels and baseline cytokines concentration with the severe clinical outcomes (ICU admission, requirement of invasive mechanical ventilation and development of Acute Respiratory Distress Syndrome). Statistical analyses were performed with SPSS software (v.19, IBM, Endicott, NY, USA) and GraphPad Prism software (v. 8.2.1, GraphPad, San Diego, CA, USA) and a $p$ value less than 0.05 was considered statistical significance. 


\section{Results}

\subsection{Demographic and Clinical Characteristics of the Studied Patients}

A total of 24 hospitalized laboratory confirmed COVID-19 patients were included in the study. The demographic and most relevant clinical characteristics related to COVID-19 are shown in Table 1 . Most, $83 \%(20 / 24)$, were males, with a median age of 61 years old (IQR: $48-75.3)$. Nearly $50 \%(12 / 24)$ of patients met obesity criteria (BMI $\geq 30)$ and $42 \%(10 / 24)$ had hypertension. The median hospitalization time was 8 days, and $21 \%$ $(5 / 24)$ were admitted to the ICU. Eight of them (33.3\%) met the criteria for severe COVID19 disease.

Table 1. Demographic and clinical characteristics of the study population.

\begin{tabular}{|c|c|}
\hline Characteristics & $n=24$ \\
\hline Age (years) & $61.0(48.0-75.3)$ \\
\hline Sex (male) & $83 \%(20)$ \\
\hline \multicolumn{2}{|l|}{ Comorbidities } \\
\hline Obesity, BMI > 30 & $50 \%(12)$ \\
\hline Hypertension & $42 \%(10)$ \\
\hline Chronic lung disease & $21 \%(5)$ \\
\hline Dyslipidemia & $21 \%(5)$ \\
\hline Cardiovascular disease & $13 \%(3)$ \\
\hline Diabetes & $13 \%(3)$ \\
\hline Hospitalization time (days) & $8.0(7.0-16.3)$ \\
\hline ICU admission & $21 \%(5)$ \\
\hline ICU length of stay (days) & $12.0(9.0-18.5)$ \\
\hline Exitus & $4 \%(1)$ \\
\hline Time from symptom onset to hospital admission (days) & $9.0(5.5-13.0)$ \\
\hline Time from hospital admission to cohort admission (days) & $2.0(2.0-3.0)$ \\
\hline Time from PCR+ to cohort admission (days) & $3.0(2.0-5.0)$ \\
\hline \multicolumn{2}{|l|}{ Symptoms on admission } \\
\hline Fever & $75 \%(18)$ \\
\hline Dyspnea & $71 \%(17)$ \\
\hline Cough & $67 \%(16)$ \\
\hline Malaise & $67 \%(16)$ \\
\hline Diarrhea & $42 \%(10)$ \\
\hline Sputum & $38 \%(9)$ \\
\hline ARDS * & $30 \%(7)$ \\
\hline Myalgia/Arthralgia & $30 \%(7)$ \\
\hline Anosmia & $25 \%(6)$ \\
\hline Chest pain & $25 \%(6)$ \\
\hline \multicolumn{2}{|l|}{ Median laboratory values on admission } \\
\hline Leukocytes (cells/mL) & $4940.0(4545.0-6815.0)$ \\
\hline Lymphocytes (cells/mL) & $955.0(755.0-1215.0)$ \\
\hline Neutrophils (cells/mL) & $3725.0(2860.0-5437.5)$ \\
\hline Platelets $\left(\times 10^{9} / \mathrm{L}\right)$ & $166.5(132.8-248.0)$ \\
\hline Creatinine (mg/dL) & $0.885(0.778-1.023)$ \\
\hline $\mathrm{LDH}(\mathrm{UI} / \mathrm{L})^{* *}$ & $274.0(208.0-350.0)$ \\
\hline Bilirubin $(\mathrm{mg} / \mathrm{dL}) * *$ & $0.660(0.430-0.900)$ \\
\hline Oxygen therapy & $58 \%(14)$ \\
\hline Invasive mechanical ventilation & $21 \%(5)$ \\
\hline Pulmonary infiltrates & $92 \%(22)$ \\
\hline \multicolumn{2}{|l|}{ Treatments during hospitalization } \\
\hline Hydroxychloroquine & $71 \%(17)$ \\
\hline Antibiotics & $46 \%(11)$ \\
\hline Immunosuppressive therapy & $46 \%(11)$ \\
\hline Corticosteroids & $42 \%(10)$ \\
\hline Lopinavir/Ritonavir & $42 \%(10)$ \\
\hline Azithromycin & $30 \%(7)$ \\
\hline
\end{tabular}




\subsection{SARS-CoV-2 Viral Load Kinetics}

The SARS-CoV-2 viral load quantification was performed from 92 RNA samples extracted from nasopharyngeal swabs in the 24 patients at different time points (24 at baseline, 18 at day 3,13 at day 6,5 at day 15,16 at month 1 , and 16 at month 3 ) (Table 2). At baseline, 23 of 24 patients (96\%) were positive for SARS-CoV-2 with a median viral load of 2227.17 copies $/ 10^{4}$ cells, showing broad variability between patients (IQR: $\left.69.78-7.42 \times 10^{4}\right)$. Only one patient (COV 015) was negative for SARS-CoV-2 RNA quantification, but he had also low amplification of RPP30, indicating a deficient sampling. Overall, SARS-CoV-2 viral load decreased overtime, and most of the patients $(80 \%)$ were negative one month after the diagnosis (Figure 1A). However, five patients showed persistent viral load at month 1 and 3. All these patients had severe disease (COV 006, COV 009 and COV 013) and/or comorbidities, such as diabetes (COV 016 and COV 013); hypertension or cardiovascular disorders (COV 016, COV 019 and COV 013); chronic lung disease and HIV infection (COV 009) and dyslipidemia (COV 006). Two different profiles in SARS-CoV-2 kinetics were observed during acute infection, based on the COVID-19 clinical outcomes. A delay in the significant decrease in SARS-CoV-2 levels during the first 6 days of follow up was recognized in those patients with severe disease. Thus, while in patients with mild/moderate disease a significant decline in viral load is observed from the diagnosis time, in patients with severe disease, this is only observed after day 6 (Figure 1B).

Table 2. SARS-CoV-2 RNA quantification from nasopharyngeal swab samples.

\begin{tabular}{ccccccc}
\hline \multicolumn{7}{c}{ SARS-CoV-2 RNA (Copies/10 $\mathbf{C}^{\mathbf{C}}{ }^{*}$ ) } \\
\hline Case & Baseline & Day 3 & Day 6 & Day 15 & Month 1 & Month 3 \\
\hline COV 001 & $1.03 \times 10^{4}$ & $4.70 \times 10^{5}$ & 202.55 & NA & ND & NA \\
COV 002 & $3.73 \times 10^{6}$ & $3.48 \times 10^{3}$ & NA & NA & ND & ND \\
COV 003 & 42.52 & 25.75 & NA & NA & ND & ND \\
COV 004 & $3.27 \times 10^{3}$ & 171.77 & NA & NA & ND & ND \\
COV 005 & 107.84 & ND & NA & NA & ND & ND \\
COV 006 & 71.27 & NA & 228.31 & ND & NA & 76 \\
COV 007 & 116.38 & 43.68 & NA & NA & ND & ND \\
COV 008 & $5.43 \times 10^{4}$ & $1.10 \times 10^{4}$ & 21.24 & NA & ND & ND \\
COV 009 & $7.08 \times 10^{4}$ & 424.73 & 9.97 & 13.67 & NA & 52.8 \\
COV 010 & 69.28 & 307.3 & NA & NA & ND & ND \\
COV 011 & $1.19 \times 10^{3}$ & NA & $1.65 \times 10^{3}$ & ND & ND & ND \\
COV 012 & $4.75 \times 10^{5}$ & NA & $1.10 \times 10^{4}$ & ND & NA & NA \\
COV 013 & $1.53 \times 10^{5}$ & $9.81 \times 10^{5}$ & 195.8 & NA & 408.3 & NA \\
COV 014 & 35.74 & 10.16 & ND & NA & ND & ND \\
COV 015 & ND & ND & NA & NA & ND & ND \\
COV 016 & $7.54 \times 10^{4}$ & $5.91 \times 10^{4}$ & NA & NA & 45.43 & 7.68 \\
COV 017 & 59.94 & NA & ND & NA & ND & ND \\
COV 018 & 5.89 & ND & NA & NA & ND & ND \\
COV 019 & $6.88 \times 10^{4}$ & $1.42 \times 10^{3}$ & NA & NA & NA & 251.4 \\
COV 020 & 946.4 & 53.6 & 81.3 & 25.2 & ND & NA \\
COV 021 & 400 & 169.51 & ND & NA & NA & NA \\
COV 022 & $3.09 \times 10^{5}$ & NA & 202.8 & NA & NA & NA \\
COV 023 & $2.56 \times 10^{6}$ & $2.37 \times 10^{5}$ & NA & NA & NA & NA \\
COV 024 & $4.42 \times 10^{3}$ & NA & 11.1 & NA & NA & NA \\
\hline
\end{tabular}

* copies $/ 10^{4}$ cel: number of viral RNA copies per $10^{4}$ cells. ND: not detected. NA: sample not collected. Patients from the COVID-19 severe group are highlighted in bold. 
A

\section{Viral load}

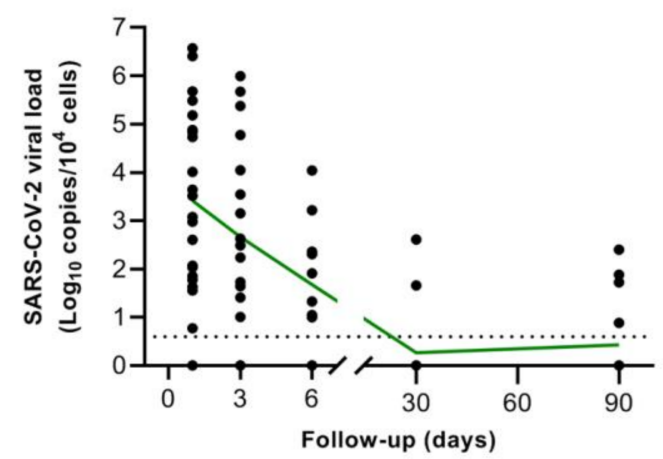

B

Viral load

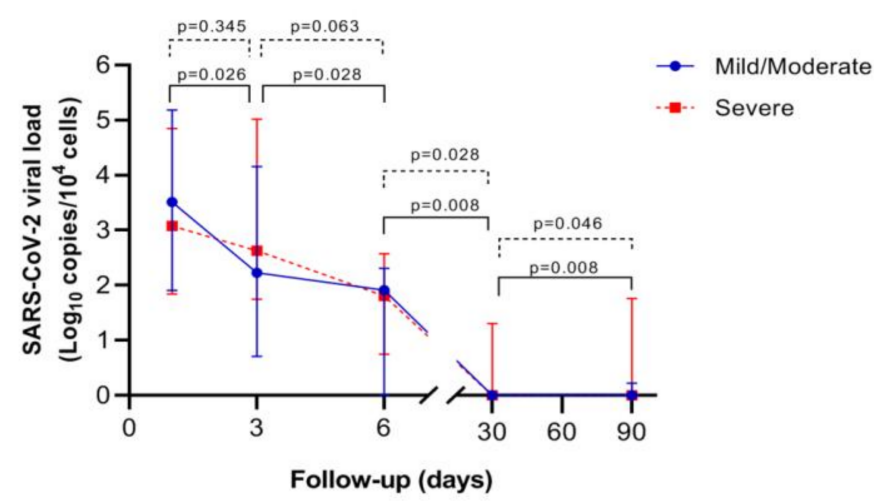

Figure 1. SARS-CoV-2 viral load kinetics. (A) SARS-CoV-2 RNA levels among the overall study population during the study period. The black dots represent the aligned individual values obtained from each time point. The green line represents the connected mean values. The dotted line indicates the established experimental threshold (below the lowest positive sample obtained in our study). (B) Median SARS-CoV-2 RNA levels in patients with mild/moderate versus severe COVID-19. The solid blue line with circles represents the mild/moderate group and dotted red line with squares represents the severe group. Wilcoxon signed rank test was performed for the decline of viral load between time points; $\mathrm{p}$ : $p$-value.

\subsection{Anti-SARS-CoV-2 Antibodies Kinetics}

The anti-SARS-CoV-2 antibodies levels were quantified at different time points, from a total of 109 serum samples (24 at baseline, 18 at day 3,13 at day 6, 5 at day 15, 16 at month 1 , 18 at month 3 and 15 at month 6) (Figure 2). Overall, a high variability in IgA baseline levels was observed among patients that progressively increased, reaching the highest median levels at day 6 of follow-up, and then significantly decreased until month $6(p=0.028)$. The highest levels of $\operatorname{IgA}$ at baseline and during the follow up were observed in patients with severe COVID-19 (COV 006, COV 008, COV 010, COV 014, COV 013) (Figure 2A). A similar pattern was observed for the kinetics of IgM, with an ongoing increase reaching the maximum levels at day 6 and with a significant decline after that $(p=0.028)$. Similar to IgA, the highest levels of $\operatorname{IgM}$ at baseline and during the follow up were observed in patients with severe COVID-19 (COV 008, COV 011, COV 010, COV 020) (Figure 2B). For $\mathrm{IgG}$, there was also a gradual increase until day 6 , with a progressive but slow decrease until month 6, reaching very low concentrations (Figure 2C). Of note is that IgG levels at month 6 were significantly higher than in a group of 30 uninfected controls (15.93 vs. $4.50 \mu \mathrm{g} / \mathrm{mL}$, respectively, $p$-value $<0.001$ ) (Figure 2D). 
A

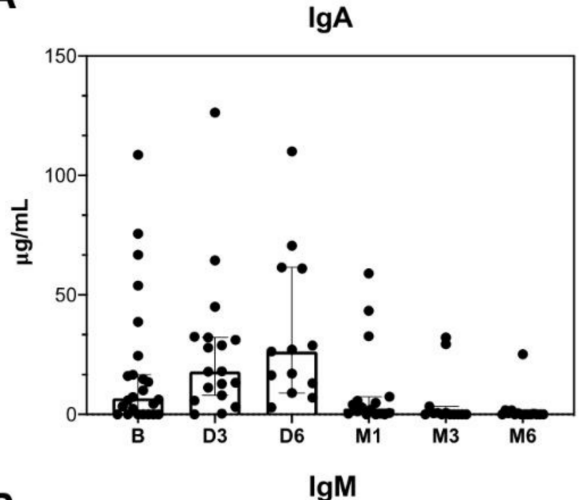

B

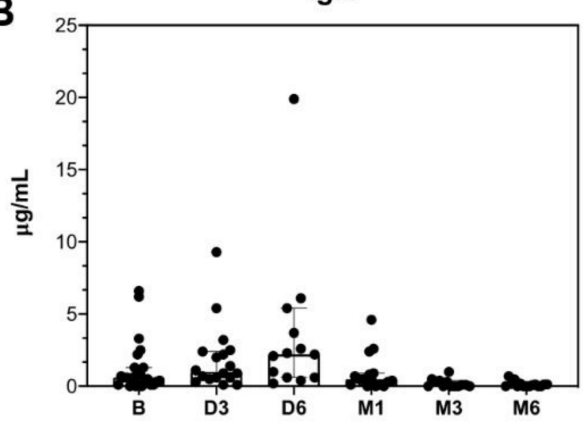

C
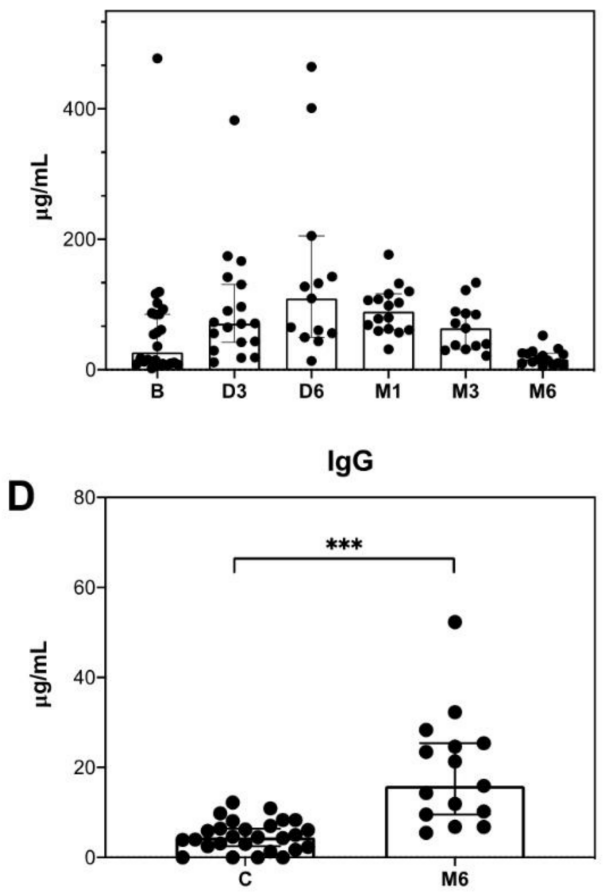

$\lg A$

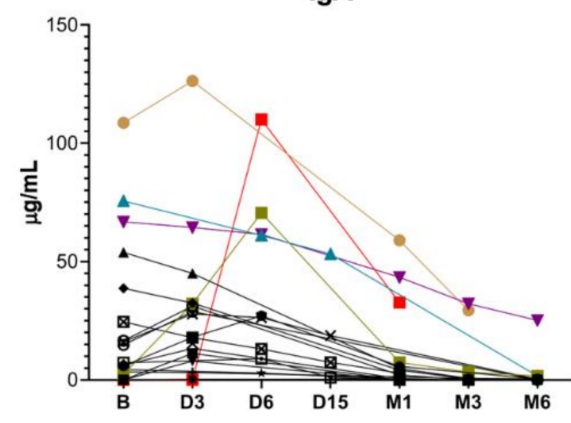

Ig M

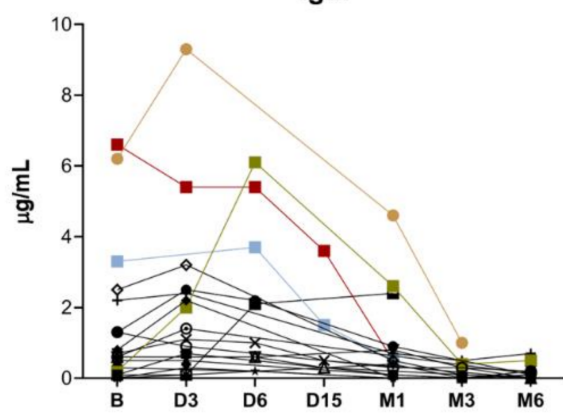

$\lg \mathbf{G}$

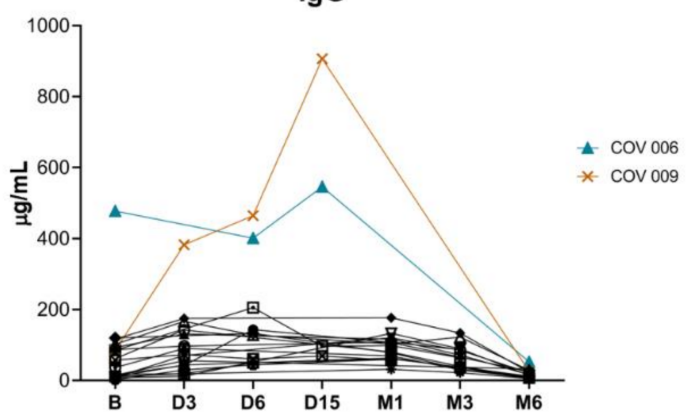

Figure 2. Absolute levels at different time points during the study period and antibodies $\operatorname{IgA}(\mathbf{A}), \operatorname{IgM}$ (B) and $\operatorname{IgG}(\mathbf{C})$ kinetics in specific patients. Absolute levels of $\operatorname{IgA}(\mathbf{A}), \operatorname{IgM}(\mathbf{B})$ and $\operatorname{IgG}(\mathbf{C})$ among the overall study population $(n=24)$ at baseline (B), day 3 (D3), day 6 (D6), month 1 (M1), month 3 (M3) and month 6 (M6) after SARS-CoV-2 infection and changes of serum IgA (A), IgM (B) and $\operatorname{IgG}(\mathrm{C})$ antibodies in specific patients $(n=19)$ at baseline (B), day 3 (D3), day 6 (D6), month 1 (M1), month 3 (M3) and month 6 (M6) after SARS-CoV-2 infection. Patients COV 006, COV 008, COV 009, COV 010, COV 011, COV 013, COV 014 and COV 020 belong to the severe group. (D) Comparison of IgG levels between uninfected controls (c) and patients after 6 months of SARS-CoV-2 infection. Mann-Whitney U test. ${ }^{* * *}, p$-value $<0.0001$. 
The numerical data for $\operatorname{IgA}, \operatorname{IgM}$ and $\operatorname{IgG}$ in serum during the study period are shown as Supplementary Data (Table S1).

\subsection{Plasma Cytokines Kinetics}

Plasma cytokines levels were performed in a total of 18 patients, 12 with mild/moderate and 6 with severe COVID-19, at different time points (18 at baseline, 15 at month 1,14 at month 3 , and 17 at month 6). Figure 3 shows the dynamic of the median concentrations of the nine cytokines assessed (TNF- $\alpha$, IL-6, IL-8, IL-1 $\beta$, MIP- $1 \alpha$, MIP- $1 \beta$, IFN- $\gamma$, sCD25 and IP-10) for each group, based on COVID-19 severity, during the study period.

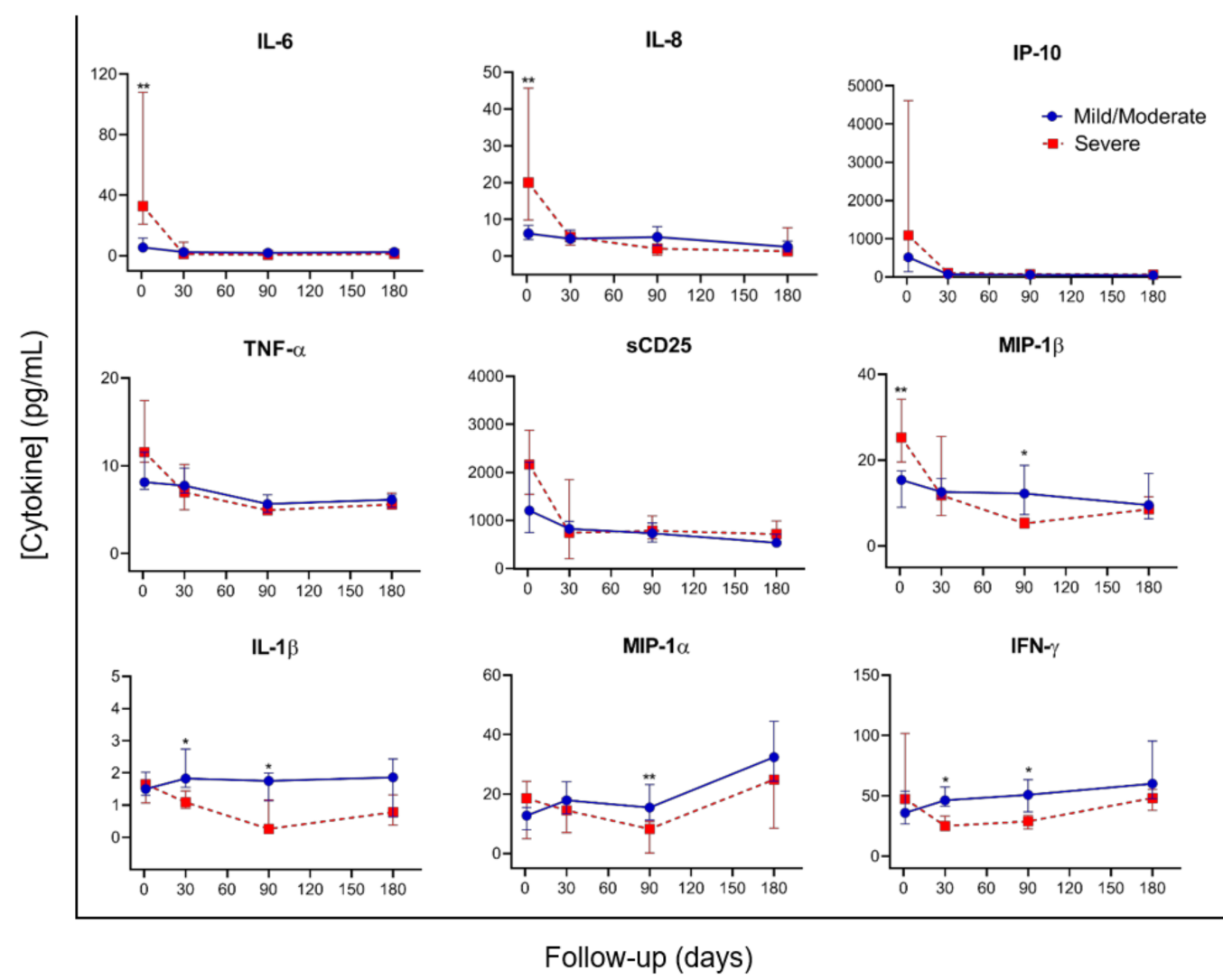

Figure 3. Cytokine kinetics in patients with mild/moderate versus severe COVID-19 during the study period. Cytokine levels are expressed as median \pm IQR. The solid blue line with circles represents the mild/moderate group $(n=12)$ and dotted red line with squares represents severe group $(n=6)$. Differences between both groups at each time point were assessed using Mann-Whitney U test. *, $p$-value $<0,05 ;{ }^{* *}, p$-value $<0.001$.

At baseline, significant higher levels of IL- 6 , IL-8, and MIP-1 $\beta$ were observed in patients with severe disease compared with those with mild/moderate COVID-19. Overall, a similar dynamic was observed for some of the proinflammatory markers, IL-6, IL-8, IP-10, TNF- $\alpha$ and sCD25, during the study period. By contrast, the dynamic of MIP-1 $\beta$, IL-1 $\beta$, MIP- $1 \alpha$ and IFN- $\gamma$ showed a different profile during the follow up, with significant higher levels at month 1 (IL-1 $\beta$ and IFN- $\gamma$ ) and month 3 (MIP-1 $\beta$, IL- $1 \beta$, MIP- $1 \alpha$ and IFN- $\gamma$ ) among patients with mild/moderate diseases, compared to those with severe COVID-19. After 6 months of the acute SARS-CoV-2 infection, no differences were found between patients with mild/moderate vs. severe disease.

The numerical data for plasma cytokines comparison between mild/moderate vs. severe patients are shown as Supplementary Data. 


\subsection{Clinical, Virological and Host Immune Biomarkers for Severe COVID-19 Outcomes}

A univariate analysis was performed to identify potential biomarkers associated with severe clinical outcomes, defined as the requirement of invasive mechanical ventilation, the admission to an intensive care unit (ICU) and the development of acute respiratory distress syndrome (ARDS). Higher levels of IgA, IgM, IgG against SARS-CoV-2 and also the cytokines IL-6, IL-8 and MIP- $1 \beta$ at baseline were observed among patients who developed ARDS compared to those without ARDS. Moreover, higher levels of IL- 6 and MIP-1 $\beta$ were related to either the need for invasive mechanical ventilation or ICU admission. Overall, SARS-CoV-2 viral load at baseline was not associated with any of the severe clinical outcome definitions (Table 3).

Table 3. Biomarkers of severe COVID-19.

\begin{tabular}{|c|c|c|c|c|c|c|}
\hline & ARDS & No ARDS & $p$-Value & $\begin{array}{c}\text { Invasive } \\
\text { Mechanical } \\
\text { Ventilation/ } \\
\text { ICU Admission }\end{array}$ & $\begin{array}{c}\text { No Invasive } \\
\text { MechanicalVentilation/ } \\
\text { ICU Admission }\end{array}$ & $p$-Value \\
\hline $\begin{array}{c}\text { SARS-CoV-2 load } \\
\left.\text { (Log } 10 \text { copies } / 10^{4} \text { cells }\right) \\
\text { Serum antibodies }{ }^{\mathrm{a}} \\
(\mu \mathrm{g} / \mathrm{mL})\end{array}$ & $2.97(1.78-4.73)$ & $3.64(1.92-5.36)$ & 0.357 & $3.07(2.70-5.01)$ & $3.51(1.71-4.88)$ & 0.804 \\
\hline $\operatorname{Ig} \mathrm{A}$ & $24.51(7.25-75.62)$ & $4.42(0.0-14.32)$ & 0.013 & $6.18(0-16.63)$ & $7.25(1.22-50.07)$ & 0.783 \\
\hline $\operatorname{IgG}$ & 84.94 (57.32-102.03) & $14.47(8.38-57.71)$ & 0.028 & $0.56(0.10-1.30)$ & $0.59(0.17-4.96)$ & 0.446 \\
\hline $\operatorname{IgM}$ & $0.66(0.59-6.25)$ & $0.43(0.09-1.06)$ & 0.047 & $17.42(8.96-86.86)$ & $57.32(6.47-281.21)$ & 0.836 \\
\hline \multicolumn{7}{|l|}{ Plasma cytokines ${ }^{\mathrm{b}}(\mathrm{pg} / \mathrm{mL})$} \\
\hline IL-6 & $32.72(20.78-107.92)$ & $5.44(2.93-11.63)$ & 0.002 & $38.51(32.72-172.42)$ & $5.80(3.72-16.57)$ & 0.017 \\
\hline IL-8 & $19.99(9.83-45.67)$ & $6.43(4.64-9.51)$ & 0.007 & $21.56(15.78-51.42)$ & $7.69(5.02-10.88)$ & 0.056 \\
\hline IP-10 & $\begin{array}{c}1083.80 \\
(439.15-4613.25)\end{array}$ & $\begin{array}{c}515.40 \\
(141.3-633.13)\end{array}$ & 0.102 & $\begin{array}{c}1606.00 \\
(1076.40-3347.00)\end{array}$ & $534.70(177.65-614.15)$ & 0.100 \\
\hline TNF- $\alpha$ & $11.55(10.40-17.45)$ & $8.12(7.32-11.56)$ & 0.083 & $10.96(10.60-11.92)$ & $10.81(7.55-11.73)$ & 0.574 \\
\hline sCD25 & $\begin{array}{c}2160.00 \\
(1541.25-2877.0)\end{array}$ & $\begin{array}{c}1221.50 \\
(775.33-2806.00)\end{array}$ & 0.250 & $\begin{array}{c}1567.00 \\
(1515.00-2247.50)\end{array}$ & $1465.00(960.95-2534.50)$ & 0.645 \\
\hline MIP-1 $\beta$ & $25.29(19.52-34.19)$ & $15.37(8.99-17.51)$ & 0.001 & $30.82(24.47-37.55)$ & $16.60(9.98-19.99)$ & 0.039 \\
\hline IL-1 $\beta$ & $1.65(1.07-1.77)$ & $1.50(1.31-2.02)$ & 0.750 & $1.62(1.42-1.73)$ & $1.60(1.30-1.80)$ & 1000 \\
\hline $\mathrm{MIP}-1 \alpha$ & $18.52(5.02-24.21)$ & $12.74(7.95-15.47)$ & 0.682 & $15.11(10.87-18.52)$ & $13.36(8.34-19.62)$ & 1.00 \\
\hline IFN- $\gamma$ & $47.59(36.60-101.63)$ & $35.91(26.79-53.89)$ & 0.213 & $42.13(40.57-77.18)$ & $37.01(30.6-53.66)$ & 0.301 \\
\hline
\end{tabular}

Data are median (IQR) Mann-Whitney U test was performed. $p$-values $<0.05$ were considered significant and are highlighted in bold.

${ }^{a}$ Performed in the following study population: ARDS $n=7$; No ARDS $n=17$; ICU admission $n=5$; No ICU admission $n=19$; ${ }^{\mathrm{b}}$ Performed in the following study population: $\operatorname{ARDS} n=6$; No ARDS $n=12$; ICU admission $n=3$; No ICU admission $n=154$.

\section{Discussion}

In this study we report that elevated levels of anti-SARS-CoV-2 antibodies, IgA, IgM, and IgG, as well as specific cytokines, such as IL-6, IL-8, MIP- $1 \beta$, during SARS-CoV-2 acute infection are associated with severe COVID-19, defined by the development of ARDS or the need for invasive mechanical ventilation or UCI admission. IgG persists after 6 months of diagnosis but at lower concentrations. Whilst the levels of some cytokines (i.e., IL-6, IL-8, IP-10, TNF- $\alpha$, sCD25) declined one month after the SARS-CoV-2 diagnosis, others (MIP-1 $\beta$, IL-1 $\beta$, MIP- $1 \alpha$ and IFN- $\gamma$ ) showed higher levels at month 1 and/or 3 in patients with mild/moderate disease compared to those with severe COVID-19. However, 6 months after diagnosis, no differences in cytokines levels between patients with mild/moderate vs. severe disease were observed. Interestingly, although SARS-CoV-2 RNA levels were not associated with the clinical outcome, during the acute infection, a significant delay in SARS-CoV-2 viral load decline was recognized in patients with severe COVID-19 as compared to those with mild/moderate COVID-19 during the first 6 days of follow up.

Overall, SARS-CoV-2 viral load kinetics follow the pattern described previously, reaching maximum levels during acute infection and decreasing progressively until becoming undetectable in most patients less than one month following diagnosis [13-16]. However, because of the close follow up of these patients, we were able to identify a significant delay during the first days of viral load decay in patients who met the criteria for severe COVID-19. Nonetheless, in our cohort, SARS-CoV-2 RNA levels were not associated with clinical outcome at any time point. There are some controversial data regarding this issue: while some studies have not reported any association between SARS-CoV-2 viral load 
during acute infection and COVID-19 severity [17,18], others point out that elevated viral load could be used to identify patients at higher risk for morbidity or severe COVID-19 outcome $[19,20]$. The controversial results may be explained by the heterogeneity of the studies related to the different characteristics of the study population and/or the methodology used for SARS-CoV-2 quantification and sampling quality (i.e., normalization using copies/cells).

Although $80 \%$ of patients showed undetectable viremia one month after diagnosis, in five patients we observed SARS-CoV-2 RNA persistence between month 1 and 3. Interestingly, all of these had severe disease and/or comorbidities (i.e., diabetes, hypertension or cardiovascular disorders, chronic lung disease and HIV infection, dyslipidemia). These observations are in agreement with previous studies that reported an association between SARS-CoV-2 RNA persistence with severe disease $[15,21]$ and comorbidity $[19,22-24]$ following remission of the acute symptoms. More recently, Jacobs et al. highlighted the association between SARS-CoV-2 plasma viremia and ICU admission [25], and Tokuyama et al. described SARS-CoV-2 persistence in intestinal enterocytes up to 7 months after symptoms resolutions [26]. Additional studies are required to better understand the clinical significance of SARS-CoV-2 persistence in different compartments (i.e., plasma, gut, upper respiratory tract) and its potential use to monitor COVID-19 patients during early acute infection and/or following the remission of acute symptoms.

We found that elevated levels of anti-SARS-CoV-2 antibodies during acute infection are related to severe COVID-19. Those patients who developed ARDS showed significantly higher levels of $\operatorname{IgA}$, IgM, and IgG, compared to patients without ARDS. These findings are in agreement with previous studies that found an association between anti-SARS-CoV-2 antibodies levels and the need for intubation or death $[27,28]$. Overall, we observed that anti-SARS-CoV-2 IgA and IgM antibodies decay rapidly after the acute infection phase (i.e., at month 3,54\% for IgA and 77\% for IgM showed levels below the limit of detection) but the decline of IgG was less prominent and persisted until month 6 . These levels were still significantly higher compared to the levels of uninfected controls (15.93 vs. $4.50 \mu \mathrm{g} / \mathrm{mL}$, respectively, $p$-value $<0.001)$. The durability of the immune responses against SARS$\mathrm{CoV}-2$ infection is a matter of intense interest and still remains unclear. Regarding the humoral responses, recent studies have also reported that IgG levels persist between 6 and 8 months after onset of symptoms [29,30]. However, plasma neutralization activity seems to decrease a few weeks after the onset of the symptoms [31]. Understanding the dynamics of antibodies against SARS-CoV-2 and the persistence of the neutralizing activity is critical to establish correct prevention and vaccination strategies.

COVID-19 severity has been associated with exacerbated inflammation due to a massive release of proinflammatory components [4,9]. We have identified that elevated levels of IL-6, IL-8, and MIP-1 $\beta$ during SARS-CoV-2 acute infection are associated with severe COVID-19, defined by the development of ARDS or the need of invasive mechanical ventilation or ICU admission. Higher levels of IL-6 have been consistently related to severe COVID-19 disease [32,33] and play a pivotal role in the cytokine storm in response to SARS-CoV-2 infection, promoting organ failure and severe lung pathology [34-36]. IL-8 leads to the activation and recruitment of neutrophils to the inflammation sites, and has been implicated in inflammatory pulmonary diseases, such as ARDS, chronic obstructive pulmonary disease, and asthma [37,38]. In addition, IL-8 has also been reported as a biomarker in predicting severe status COVID-19 patients [10]. MIP-1 $\beta$ drives the recruitment of a variety of innate and adaptive immune cells, and high concentrations have been reported in the serum and lungs of patients with certain acute respiratory viral infections $[39,40]$. However, their role during SARS-CoV-2 infection remains unclear. Some studies have reported a higher production of MIP-1 $\beta$ at the transcriptional level in bronchoalveolar lavage cells isolated from the lungs of severe COVID-19 patients [41,42], whilst other studies did not find an association between MIP-1 $\beta$ and severe disease $[34,43]$.

The levels of IL-6, IL- 8 , and MIP- $1 \beta$ significantly decline at month 1 in patients with severe COVID-19, showing during the subsequent follow up levels similar to those found 
in patients with mild/moderate disease. Overall, a similar dynamic was observed for IP-10, TNF- $\alpha$ and sCD25, during the study period. By contrast, the dynamic of MIP-1 $\beta$, IL-1 $\beta$, MIP-1 $\alpha$ and IFN- $\gamma$ showed a different evolution pattern, with a significant increase at month 1 and/or 3 among patients with mild/moderate disease, compared to those with severe COVID-19. No differences were observed in the levels of these cytokines 6 months after the acute SARS-CoV-2 infection, between patients with mild/moderate vs. severe disease. Therefore, the unbalance in the cytokine levels between severe and mild/moderate COVID-19 patients seems to be restored after 6 months of SARS-CoV-2 infection. A previous study by Lucas et al. [44] also reported no differences in the IL-6, IL-8 and IP-10 levels between mild/moderate and severe outcomes after 20 days of follow up.

This study presents some limitations. First, the relatively small size of the study population is mainly represented by men as, during the first wave of COVID-19 in our institution, $86 \%$ of hospitalized patients were men. However, we were able to accomplish a very close follow up of the clinical outcomes, viral and host immune factors in this population allowing interesting observations. Although we have identified IgG after 6 months of SARS-CoV-2 infection, we did not assess their neutralization activity and, therefore, the risk upon new SARS-CoV-2 reinfections. External validation should be assessed to confirm the predictive value of our findings.

In conclusion, in a well characterized cohort of hospitalized COVID-19 patients with mild/moderate and severe disease and close clinical follow up during and after 6 months of SARS-CoV-2 infection, we have recognized early host immune predictors of severity. Higher levels of IgA, IgM, and IgG and the specific cytokines IL-6, IL-8, and MIP-1 $\beta$ during acute infection were observed in those patients with a severe COVID-19 outcome. Conversely, higher levels of IL- $1 \beta$ and IFN- $\gamma$ at month 1 , and MIP-1 $\beta$, IL-1 $\beta$, MIP-1 $\alpha$ and IFN- $\gamma$ at month 3 , were observed among patients with mild/moderate diseases, compared to those with severe COVID-19. IgG against SARS-CoV-2 persisted after 6 months of the diagnosis.

Supplementary Materials: The following are available online at https:/ / www.mdpi.com/article/10. 3390 / microorganisms9112259/s1, Figure S1: Linear regression analysis of the RT-ddPCR SARS-CoV2 assay; Table S1: IgA, IgM, IgG levels at the different points of the study periods; Table S2: Cytokine levels (severe vs. moderate).

Author Contributions: Conceptualization and study supervision: E.P. Patient recruitment, samples and clinical data acquisition: A.P., J.J.C.-A. and M.C. Cohort management and sample processing: M.M.B., L.P., and H.C. Methodology and sample measurement: I.V., A.G.-V., V.S., M.B.-G., M.T.-R., A.S.-G., E.M.-M., C.K.O. and E.R.-M. Statistical analysis: C.M. Results analysis, interpretation and manuscript writing: H.C., I.V., E.R.-M. and E.P. All authors have read and agreed to the final version of the manuscript.

Funding: This work was supported by the Plan Estatal de I+D+I 2013-2016 and 2017-2020 and cofinanced by the Instituto de Salud Carlos III (ISCIII)—Subdirección General de Evaluación y Fomento de la investigación del Fondo Europeo de Desarrollo Regional (FEDER), Fondo COVID19 of Instituto de Salud Carlos III (COV20/00698), RETICS, Red de Investigación en SIDA [RD16/0025/0026]; and Fundación Biomédica Galicia Sur. E.R-M. was supported by the Spanish Research Council (CSIC) and by the research grant CV20-85418 from the Consejería de Transformación Económica, Industria, Conocimiento y Universidades (Junta de Andalucía). A.P. was supported by the Instituto de Salud Carlos III, Subprograma Rio Hortega (CM20/00243). A.G.-V. was supported by the Instituto de Salud Carlos III, cofinanced by the European Development Regional Fund ("A way to achieve Europe"), Subprograma Miguel Servet (CP19/00159). E.M.M. was supported by the Instituto de Salud Carlos III, cofinanced by the European Development Regional Fund ("A way to achieve Europe"), Subprogram PFIS (FI19/00304). C.K. was supported by Fondo COVID19 of Instituto de Salud Carlos III (COV20/00823).

Institutional Review Board Statement: The study was conducted according to the guidelines of the Declaration of Helsinki, and approved by the Galician Clinical Research Ethics Committee (CEIm-g, ref: 2020/196, signed on 10 April 2020). 
Informed Consent Statement: Informed consent was obtained from all subjects involved in the study.

Data Availability Statement: Not applicable.

Acknowledgments: We would like to thank all the members of COHVID-GS and IISGS Biobank, patients, nursing staff and Celta Ingenieros (A Coruña, Spain) for their kind supply of ddPCR reagents. Members of COHVID-GS (Galicia Sur Health Research Institute): Alejandro Araujo, Jorge Julio Cabrera, Víctor del Campo, Manuel Crespo, Alberto Fernández, Beatriz Gil de Araujo, Carlos Gómez, Virginia Leiro, María Rebeca Longueira, Ana López-Domínguez, José Ramón Lorenzo, María Marcos, Alexandre Pérez, María Teresa Pérez, Lucia Patiño, Sonia Pérez, Silvia Pérez-Fernández, Eva Poveda, Cristina Ramos, Benito Regueiro, Cristina Retresas, Tania Rivera, Olga Souto, Isabel Taboada, Susana Teijeira, María Torres, Vanesa Val, Irene Viéitez.

Conflicts of Interest: The authors declare that the research was conducted in the absence of any commercial or financial relationships that could be construed as a potential conflict of interest.

\section{References}

1. Chen, N.; Zhou, M.; Dong, X.; Qu, J.; Gong, F.; Han, Y.; Qiu, Y.; Wang, J.; Liu, Y.; Wei, Y.; et al. Epidemiological and clinical characteristics of 99 cases of 2019 novel corona-virus pneumonia in Wuhan, China: A descriptive study. Lancet 2020, 395, 507-513. [CrossRef]

2. Xu, Z.; Shi, L.; Wang, Y.; Zhang, J.; Huang, L.; Zhang, C.; Liu, S.; Zhao, P.; Liu, H.; Zhu, L.; et al. Pathological findings of COVID-19 associated with acute respiratory distress syndrome. Lancet Respir. Med. 2020, 8, 420-422. [CrossRef]

3. Hu, J.; Wang, Y. The Clinical Characteristics and Risk Factors of Severe COVID-19. Gerontology 2021, 67, 255-266. [CrossRef] [PubMed]

4. Qin, C.; Zhou, L.; Hu, Z.; Zhang, S.; Yang, S.; Tao, Y.; Xie, C.; Ma, K.; Shang, K.; Wang, W.; et al. Dysregulation of Immune Response in Patients With Coronavirus 2019 (COVID-19) in Wuhan, China. Clin. Infect. Dis. 2020, 71, 762-768. [CrossRef]

5. Guo, L.; Ren, L.; Yang, S.; Xiao, M.; Chang, D.; Yang, F.; Cruz, C.S.D.; Wang, Y.; Wu, C.; Xiao, Y.; et al. Profiling Early Humoral Response to Diagnose Novel Coronavirus Disease (COVID-19). Clin. Infect. Dis. 2020, 71, 778-785. [CrossRef]

6. Zhao, J.; Yuan, Q.; Wang, H.; Liu, W.; Liao, X.; Su, Y.; Wang, X.; Yuan, J.; Li, T.; Li, J.; et al. Antibody Responses to SARS-CoV-2 in Patients With Novel Coronavirus Disease 2019. Clin. Infect. Dis. 2020, 71, 2027-2034. [CrossRef]

7. Isho, B.; Abe, K.T.; Zuo, M.; Jamal, A.J.; Rathod, B.; Wang, J.H.; Li, Z.; Chao, G.; Rojas, O.L.; Bang, Y.M.; et al. Persistence of Serum and Saliva Anti-body Responses to SARS-CoV-2 Spike Antigens in COVID-19 Patients. Sci. Immunol. 2020, 5, eabe5511.

8. Ripperger, T.J.; Uhrlaub, J.L.; Watanabe, M.; Wong, R.; Castaneda, Y.; Pizzato, H.A.; Thompson, M.R.; Bradshaw, C.; Weinkauf, C.C.; Bime, C.; et al. Orthogonal SARS-CoV-2 Serological Assays Enable Surveillance of Low-Prevalence Communities and Reveal Dura-ble Humoral Immunity. Immunity 2020, 53, 925-933. [CrossRef]

9. Ye, Q.; Wang, B.; Mao, J. The pathogenesis and treatment of the 'Cytokine Storm' in COVID-19. J. Infect. 2020, 80, 607-613. [CrossRef]

10. Li, L.; Li, J.; Gao, M.; Fan, H.; Wang, Y.; Xu, X.; Chen, C.; Liu, J.; Kim, J.; Aliyari, R.; et al. Interleukin-8 as a Biomarker for Disease Prognosis of Coronavirus Disease-2019 Patients. Front. Immunol. 2021, 11, 602395. [CrossRef]

11. Ghazavi, A.; Ganji, A.; Keshavarzian, N.; Rabiemajd, S.; Mosayebi, G. Cytokine profile and disease severity in patients with COVID-19. Cytokine 2021, 137, 155323. [CrossRef]

12. WHO Guidance. Available online: https://www.who.int/publications/i/item/WHO-2019-nCoV-clinical-2021-1 (accessed on 25 January 2021).

13. Walsh, K.A.; Jordan, K.; Clyne, B.; Rohde, D.; Drummond, L.; Byrne, P.; Ahern, S.; Carty, P.G.; O’Brien, K.K.; O’Murchu, E.; et al. SARS-CoV-2 detection, viral load and infectivity over the course of an infection. J. Infect. 2020, 81, 357-371. [CrossRef]

14. He, X.; Lau, E.H.Y.; Wu, P.; Deng, X.; Wang, J.; Hao, X.; Lau, Y.C.; Wong, J.Y.; Guan, Y.; Tan, X.; et al. Temporal dynamics in viral shedding and transmissibility of COVID-19. Nat. Med. 2020, 26, 672-675. [CrossRef]

15. Néant, N.; Lingas, G.; le Hingrat, Q.; Ghosn, J.; Engelmann, I.; Lepiller, Q.; Gaymard, A.; Ferré, V.; Hartard, C.; Plantier, J.C.; et al. Modeling SARS-CoV-2 viral kinetics and association with mortality in hospitalized patients from the French COVID cohort. Proc. Natl. Acad. Sci. USA 2021, 118, e2017962118. [CrossRef]

16. Alteri, C.; Cento, V.; Antonello, M.; Colagrossi, L.; Merli, M.; Ughi, N.; Renica, S.; Matarazzo, E.; di Ruscio, F.; Tartaglione, L.; et al. Detection and quantification of SARS-CoV-2 by droplet digital PCR in real-time PCR negative na-sopharyngeal swabs from suspected COVID-19 patients. PLoS ONE 2020, 15, e0236311. [CrossRef]

17. Argyropoulos, K.V.; Serrano, A.; Hu, J.; Black, M.; Feng, X.; Shen, G.; Call, M.; Kim, M.J.; Lytle, A.; Belovarac, B.; et al. Association of Initial Viral Load in Severe Acute Respiratory Syndrome Coronavirus 2 (SARS-CoV-2) Patients with Outcome and Symptoms. Am. J. Pathol. 2020, 190, 1881-1887. [CrossRef]

18. le Borgne, P.; Solis, M.; Severac, F.; Merdji, H.; Ruch, Y.; Alamé Intern, K.; Bayle, E.; Hansmann, Y.; Bilbault, P.; Fafi-Kremer, S.; et al. SARS-CoV-2 viral load in nasopharyngeal swabs in the emergency department does not predict COVID-19 severity and mortality. Acad. Emerg. Med. 2021, 28, 306-313. [CrossRef] 
19. Komissarov, A.; Molodtsov, I.; Ivanova, O.; Maryukhnich, E.; Kudryavtseva, S.; Mazus, A.; Nikonov, E.; Vasilieva, E. High SARS-CoV-2 load in the nasopharynx of patients with a mild form of COVID-19 is associated with clinical deterioration regardless of the hydroxychloroquine administration. PLoS ONE 2021, 16, e0246396. [CrossRef]

20. Maltezou, H.C.; Raftopoulos, V.; Vorou, R.; Papadima, K.; Mellou, K.; Spanakis, N.; Kossyvakis, A.; Gioula, G.; Exindari, M.; Froukala, E.; et al. Association Between Upper Respiratory Tract Viral Load, Comorbidities, Disease Severity, and Outcome of Patients With SARS-CoV-2 Infection. J. Infect. Dis. 2021, 223, 1132-1138. [CrossRef]

21. Lescure, F.-X.; Bouadma, L.; Nguyen, D.; Parisey, M.; Wicky, P.-H.; Behillil, S.; Gaymard, A.; Bouscambert-Duchamp, M.; Donati, F.; Le Hingrat, Q.; et al. Clinical and virological data of the first cases of COVID-19 in Europe: A case series. Lancet Infect. Dis. 2020, 20, 697-706. [CrossRef]

22. Buetti, N.; Trimboli, P.; Mazzuchelli, T.; lo Priore, E.; Balmelli, C.; Trkola, A.; Conti, M.; Martinetti, G.; Elzi, L.; Ceschi, A.; et al. Diabetes mellitus is a risk factor for prolonged SARS-CoV-2 viral shedding in lower respiratory tract samples of critically ill patients. Endocrine 2020, 70, 454-460. [CrossRef] [PubMed]

23. Fu, Y.; Han, P.; Zhu, R.; Bai, T.; Yi, J.; Zhao, X.; Tao, M.; Quan, R.; Chen, C.; Zhang, Y.; et al. Risk factors for viral RNA shedding in COVID-19 patients. Eur. Respir. J. 2020, 56, 2001190. [CrossRef] [PubMed]

24. Atmosudigdo, I.S.; Pranata, R.; Lim, M.A.; Henrina, J.; Yonas, E.; Vania, R.; Radi, B. WITHDRAWN: Dyslipidemia Increases the Risk of Severe COVID-19: A Systematic Review, Meta-analysis, and Meta-regression. J. Clin. Exp. Hepatol. 2021. [CrossRef] [PubMed]

25. Jacobs, J.L.; Staines, B.; Bain, W.; da Silva Castanha, P.; Naqvi, A.; Boltz, V.F.; Marques, E.T.; Denny, T.; Woods, C.; Morris, A.; et al. COVID-19 outcome: Insights from quantification of viremia and neutralizing antibody, abstr 116, p 32. Abstracts From the virtual CROI 2021 Conference on Retroviruses and Opportunistic Infections. Clin. Infect. Dis. 2021, 686. [CrossRef]

26. Tokuyama, M.; Ladinsky, M.S.; Jha, D.; Cossarini, F.; Livanos, A.E.; Reidy, J.; Tankelevich, M.; Mar-tinez-Delgado, G.; Bjorkman, P.J.; Mehandru, S. SARS-COV-2 persists in intestinal enterocytes up to 7 months after symptom resolution, abstr 115, p 31. In Proceedings of the Abstracts from the Virtual CROI 2021 Conference on Retroviruses and Opportunistic Infections, San Francisco, CA, USA, 3 June-3 November 2021.

27. Garcia-Beltran, W.F.; Lam, E.C.; Astudillo, M.G.; Yang, D.; Miller, T.E.; Feldman, J.; Hauser, B.M.; Caradonna, T.M.; Clayton, K.L.; Nitido, A.D.; et al. COVID-19-neutralizing antibodies predict disease severity and survival. Cell 2021, 184, 476-488. [CrossRef]

28. Long, Q.-X.; Liu, B.-Z.; Deng, H.-J.; Wu, G.-C.; Deng, K.; Chen, Y.-K.; Liao, P.; Qiu, J.-F.; Lin, Y.; Cai, X.-F.; et al. Antibody responses to SARS-CoV-2 in patients with COVID-19. Nat. Med. 2020, 26, 845-848. [CrossRef]

29. Dan, J.M.; Mateus, J.; Kato, Y.; Hastie, K.M.; Yu, E.D.; Faliti, C.E.; Grifoni, A.; Ramirez, S.I.; Haupt, S.; Frazier, A.; et al. Immunological memory to SARS-CoV-2 assessed for up to 8 months after infection. Science 2021, 371, eabf4063. [CrossRef]

30. Gaebler, C.; Wang, Z.; Lorenzi, J.C.C.; Muecksch, F.; Finkin, S.; Tokuyama, M.; Cho, A.; Jankovic, M.; Schaefer-Babajew, D.; Oliveira, T.Y.; et al. Evolution of antibody immunity to SARS-CoV-2. Nature 2021, 591, 639-644. [CrossRef]

31. Beaudoin-Bussières, G.; Laumaea, A.; Anand, S.P.; Prévost, J.; Gasser, R.; Goyette, G.; Medjahed, H.; Perreault, J.; Tremblay, T.; Lewin, A.; et al. Decline of Humoral Responses against SARS-CoV-2 Spike in Convalescent Individuals. mBio 2020, 11, e02590-20. [CrossRef]

32. Santa Cruz, A.; Mendes-Frias, A.; Oliveira, A.I.; Dias, L.; Matos, A.R.; Carvalho, A.; Capela, C.; Pedrosa, J.; Castro, A.G.; Silvestre, R. Interleukin-6 Is a Biomarker for the Development of Fatal Severe Acute Respiratory Syndrome Coronavirus 2 Pneumonia. Front. Immunol. 2021, 12, 613422. [CrossRef]

33. del Valle, D.M.; Kim-Schulze, S.; Huang, H.-H.; Beckmann, N.D.; Nirenberg, S.; Wang, B.; Lavin, Y.; Swartz, T.H.; Madduri, D.; Stock, A.; et al. An inflammatory cytokine signature predicts COVID-19 severity and survival. Nat. Med. 2020, 26, 1636-1643. [CrossRef]

34. Huang, C.; Wang, Y.; Li, X.; Ren, L.; Zhao, J.; Hu, Y.; Zhang, L.; Fan, G.; Xu, J.; Gu, X.; et al. Clinical features of patients infected with 2019 novel coronavirus in Wuhan, China. Lancet 2020, 395, 497-506. [CrossRef]

35. Chen, G.; Wu, D.; Guo, W.; Cao, Y.; Huang, D.; Wang, H.; Wang, T.; Zhang, X.; Chen, H.; Yu, H.; et al. Clinical and immunological features of severe and moderate coronavirus disease 2019. J. Clin. Investig. 2020, 130, 2620-2629. [CrossRef]

36. Blanco-Melo, D.; Nilsson-Payant, B.E.; Liu, W.-C.; Uhl, S.; Hoagland, D.; Møller, R.; Jordan, T.X.; Oishi, K.; Panis, M.; Sachs, D.; et al. Imbalanced Host Response to SARS-CoV-2 Drives Development of COVID-19. Cell 2020, 18, 1036-1045.e9. [CrossRef]

37. Liu, J.; Li, S.; Liu, J.; Liang, B.; Wang, X.; Wang, H.; Li, W.; Tong, Q.; Yi, J.; Zhao, L.; et al. Longitudinal characteristics of lymphocyte responses and cytokine profiles in the peripheral blood of SARS-CoV-2 infected patients. EBioMedicine 2020, 55, 102763. [CrossRef]

38. Mukaida, N. Pathophysiological roles of interleukin-8/CXCL8 in pulmonary diseases. Am. J. Physiol. Cell. Mol. Physiol. 2003, 284, L566-L577. [CrossRef]

39. Melchjorsen, J.; Sørensen, L.N.; Paludan, S.R. Expression and function of chemokines during viral infections: From molecular mechanisms to in vivo function. J. Leukoc. Biol. 2003, 74, 331-343. [CrossRef]

40. Nuriev, R.; Johansson, C. Chemokine regulation of inflammation during respiratory syncytial virus infection. F1000Research 2019, 8, 1837. [CrossRef]

41. Liao, M.; Liu, Y.; Yuan, J.; Wen, Y.; Xu, G.; Zhao, J.; Cheng, L.; Li, J.; Wang, X.; Wang, F.; et al. Single-cell landscape of bronchoalveolar immune cells in patients with COVID-19. Nat. Med. 2020, 26, 842-844. [CrossRef] 
42. Lee, J.S.; Park, S.; Jeong, H.W.; Ahn, J.Y.; Choi, S.J.; Lee, H.; Choi, B.; Nam, S.K.; Sa, M.; Kwon, J.-S.; et al. Immunophenotyping of COVID-19 and influenza highlights the role of type I interferons in development of severe COVID-19. Sci. Immunol. 2020, 5, eabd1554. [CrossRef]

43. Chi, Y.; Ge, Y.; Wu, B.; Zhang, W.; Wu, T.; Wen, T.; Liu, J.; Guo, X.; Huang, C.; Jiao, Y.; et al. Serum Cytokine and Chemokine Profile in Relation to the Severity of Coronavirus Disease 2019 in China. J. Infect. Dis. 2020, 222, 746-754. [CrossRef]

44. Lucas, C.; Wong, P.; Klein, J.; Castro, T.B.R.; Silva, J.; Sundaram, M.; Ellingson, M.K.; Mao, T.; Oh, J.E.; Israelow, B.; et al. Longitudinal analyses reveal immunological misfiring in severe COVID-19. Nat. Cell Biol. 2020, 584, 463-469. [CrossRef] 